\title{
Pengaruh Variasi Konsentrasi Ekstrak Daun Alpukat (Persea americana M.) sebagai Inhibitor pada Baja SS-304 dalam Larutan HCl 1M
}

\author{
Windy Mustika Sari ${ }^{(1)^{*}}$, Syafriadi $^{(1)}$, Ediman Ginting Suka $^{(1)}$ \\ (1) Jurusan Fisika FMIPA Universitas Lampung \\ Jl. Prof. Dr. Soemantri Brodjonegoro 1, Bandar Lampung, 35141 \\ *email:windymustikas@gmail.com*,ssyafriadi155@gmail.com,edimanginting137@gmail.com \\ Diterima (4 April 2019), direvisi (08 Agustus 2019)
}

\begin{abstract}
Avocado leaves extract (Persea americana M.) is used as an inhibitor to the sample of SS-304 Stainless steel which cures in HCl $1 M$ Corrosive Medium for 168 hours, the inhibitor concentration variation added $0 \%, 2 \%, 4 \%, 6 \%, 8 \%$ and $10 \%$ respectively. The corrosion rate is measured by using loss-weight method. The results show the lowest samples is $0,37 \mathrm{~mm} / \mathrm{y}$ of $6 \%$ and the highest $10,75 \mathrm{~mm} / \mathrm{y}$ of $0 \%$. Inhibitor efficiency to the sample SS-304 Stainless steel potrays the effectively progress to $96,55 \%$ with $6 \%$ concentration. X-Ray Diffaraction Results accquired BCC and FCC with Fe- $\alpha$ dan Fe- $\gamma$ phase along with SEM that forms agglomeration, cracked, and hole which result on its corrosion. In addition EDS contains Oxygen $(\mathrm{O})$ and Chlorine $(\mathrm{Cl})$ Element which indicate that stainless still has affected by corrotion. Thus from three samples which characterized and measured show that avocado leaves effectively as an inhibitor to the sample SS-304 stainless steel in $\mathrm{HCl} 1 \mathrm{M}$ corrosive medium.
\end{abstract}

Key words: SS-304 Stainless steel, avocado leaves exctract, inhibitor, SEM-EDS and XRD.

\begin{abstract}
Abstrak. Ekstrak daun alpukat (Persea americana M.) digunakan sebagai inhibitor pada sampel baja SS-304. Perendaman sampel baja dilakukan dalam medium korosif $\mathrm{HCl} 1 \mathrm{M}$ selama 168 jam dengan variasi konsentrasi inhibitor $0 \%, 2 \%, 4 \%, 6 \%, 8 \%$ dan $10 \%$. Laju korosi dihitung dengan menggunakan metode kehilangan massa. Diperoleh hasil perhitungan laju korosi terendah pada sampel baja SS-304 dengan konsentrasi $6 \%$ sebesar $0,37 \mathrm{~mm} / \mathrm{y}$ dan laju korosi tertinggi pada sampel baja SS-304 dengan konsentrasi $0 \%$ sebesar $10,75 \mathrm{~mm} / \mathrm{y}$. Efisiensi inhibitor paling optimum pada sampel baja SS-304 dengan inhibitor $6 \%$ sebesar 96,55\%. Hasil karakterisasi XRD menunjukkan bahwa struktur kristal yang terbentuk merupakan BCC dan FCC dengan fasa Fe- $\alpha$ dan Fe- $\gamma$. Karakterisasi SEM menunjukkan morfologi permukaan sampel adanya gumpalan, retakan serta lubang yang merupakan produk korosi. Karakterisasi EDS pada sampel baja terdapat unsur Oksigen $(\mathrm{O})$ dan Clorin $(\mathrm{Cl})$ yang mengindikasikan bahwa sampel baja telah terkorosi. Dari ketiga hasil karakterisasi dan perhitungan laju korosi menunjukkan bahwa ekstrak daun alpukat efektif sebagai inhibitor pada baja SS-304 dalam medium korosif $\mathrm{HCl} 1 \mathrm{M}$.
\end{abstract}

Kata Kunci: Baja SS-304, ekstrak daun alpukat, inhibitor, SEM-EDS dan XRD.

\section{PENDAHULUAN}

Baja tahan karat (stainless steel) merupakan satu material yang banyak digunakan dalam bidang industri. Baja SS304 merupakan baja paduan dengan kandungan $\mathrm{Cr} 18-20 \%$, dan $\mathrm{Ni} 8-10,5 \%$ [1]. Namun penggunaan baja dalam industri menyebabkan baja sering berinteraksi dengan cairan maupun gas bertekanan tinggi yang menyebabkan timbulnya karat pada permukaan baja. Kata korosi berasal dari bahasa Latin, yaitu corrodere yang artinya perusakan logam [2]. Korosi merupakan proses perusakan material karena bereaksi dengan lingkungannya [3]. Penambahan inhibitor merupakan salah satu cara yang paling efektif untuk mencegah 
korosi karena dalam penggunaannya memerlukan biaya relatif murah dan prosesnya sederhana [4]. Inhibitor korosi merupakan zat atau bahan yang apabiladitambahkan dalam konsentrasi kecil ke dalam medium korosif dapat menurunkan atau mencegah laju korosi logam [5]. Saat ini sedang dikembangkan green inhibitor yang bersifat non-toksik, murah, sudah tersedia di alam, mudah diperbaharui dan tidak merusak lingkungan [6]. Green inhibitor ini berasal dari tumbuh-tumbuhan atau biji-bijian yang diketahui mempunyai kemampuan menghambat korosi [7]. Daun alpukat mengandung senyawa flavonoid, tanin katekat, kuinon, saponin, dan steroid atau triterpenoid [8]. Kandungan tanin dalam daun alpukat yaitu 22,07\% [9].

Berdasarkan beberapa penjelasan yang telah dipaparkan, maka dalam penelitian ini akan digunakan ekstrak daun alpukat sebagai inhibitor korosi baja SS304 dalam medium korosif $\mathrm{HCl} 1 \mathrm{M}$. Pada penelitian ini dilakukan pengukuran sampel baja dengan metode kehilangan massa untuk mengetahui pengaruh ekstrak daun alpukat terhadap laju korosi pada sampel baja. Kemudian dilakukan analisis menggunakan XRD untuk mengetahui struktur kristal yang terbentuk pada baja SS-304 dan analisis SEM-EDS untuk mengetahui struktur mikro pada permukaan baja SS-304.

\section{METODE PENELITIAN}

Bahan yang digunakan dalam penelitian adalah baja SS-304, daun alpukat, larutan $\mathrm{HCl} 1 \mathrm{M}$, etanol $96 \%$, dan aquades. Proses preparasi baja SS-304 dilakukan dengan memotong baja dengan ukuran $20 \mathrm{~mm} \quad$ x $20 \mathrm{~mm} \quad$ x $10 \mathrm{~mm}$. Membersihkan sampel baja menggunakan kertas. Kemudian preparasi daun alpukat dilakukan dengan metode ekstraksi. Menyiapkan daun aplukat sebanyak 4000 gram. Mengeringkan daun alpukat selama
30 hari dibawah sinar matahari. Daun alpukat direndam dengan etanol $96 \%$ selama 1 hari. Menyaring hasil perendaman dengan kertas saring. Menguapkan filtrate menggunakan rotary evaporator dengan kecepatan $200 \mathrm{rpm}$ pada suhu $50^{\circ} \mathrm{C}$. Pembuatan larutan $\mathrm{HCl} 1 \mathrm{M}$ yaitu dengan metode pengenceran, yaitu $83 \mathrm{ml} \mathrm{HCl}$ dilarutkan dengan aquades sampai volume $1000 \mathrm{ml}$. Setelah semua bahan selesai dipreprasi, tahap selanjutnya yaitu perendaman. Pada tahap ini baja SS-304 yang sudah ditimbang massanya, dimasukkan ke dalam medium korosif yaitu larutan $\mathrm{HCl} 1 \mathrm{M}$ dengan konsentrasi inhibitor $0 \%, 2 \%, 4 \%, 6 \%, 8 \%$ dan $10 \%$ selama 168 jam. Setelah perendaman selesai, sampel baja ditimbang massa nya kembali kemudian dikarakterisasi menggunakan XRD dan SEM-EDS.

\section{HASIL DAN PEMBAHASAN}

\section{Hasil Perhitungan Laju Korosi}

Hasil perhitungan laju korosi baja SS304 dengan konsentrasi inhibitor 0\%, 2\%, $4 \%, 6 \%, 8 \%$ dan $10 \%$ dalam medium korosif $\mathrm{HCl} 1 \mathrm{M}$ ditunjukkan pada Gambar 1. Gambar 1 menunjukkan laju korosi pada konsentrasi inhibitor $0 \%, 2 \%, 4 \%$ dan $6 \%$ laju korosi menurun sebesar 10,75 $\mathrm{mm} / \mathrm{y}, 5,64 \mathrm{~mm} / \mathrm{y}, 3,17 \mathrm{~mm} / \mathrm{y}$ dan 0,37 $\mathrm{mm} / \mathrm{y}$. Namun pada konsentrasi inhibitor $8 \%$ dan $10 \%$ laju korosi meningkat sebesar $1,88 \mathrm{~mm} / \mathrm{y}$ dan $6,07 \mathrm{~mm} / \mathrm{y}$. Berdasarkan perhitungan diperoleh laju korosi tertinggi yaitu pada baja SS-304 dengan konsentrasi inhibitor $0 \%$ sebesar $10,75 \mathrm{~mm} / \mathrm{y}$. 
Tabel 1. Hasil pengukuran baja SS-304 dalam larutan $\mathrm{HCl} 1 \mathrm{M}$

\begin{tabular}{ccccc}
\hline Sampel & $\mathbf{p}(\mathbf{c m})$ & $\mathbf{I}(\mathbf{c m})$ & $\mathbf{t}(\mathbf{c m})$ & $\begin{array}{c}\mathbf{r} \\
(\mathbf{c m})\end{array}$ \\
\hline SS304-0 & 2,0850 & 2,0070 & 0,9880 & 0,2 \\
SS304-2 & 1,9720 & 1,9710 & 1,0000 & 0,2 \\
SS304-4 & 2,0130 & 1,9570 & 1,0400 & 0,2 \\
SS304-6 & 2,0050 & 1,9030 & 1,0100 & 0,2 \\
SS304-8 & 2,1200 & 1,9030 & 0,9820 & 0,2 \\
SS304-10 & 2,0500 & 1,9840 & 1,0700 & 0,2 \\
\hline
\end{tabular}

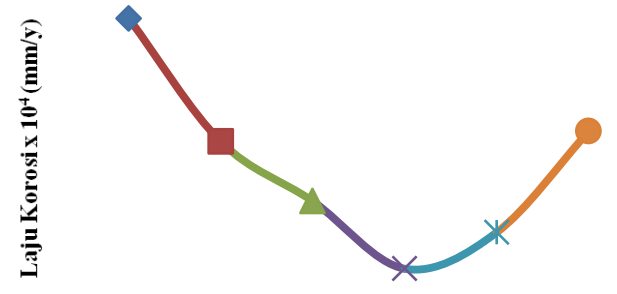

Konsentrasi Inhibitor (\%)

Gambar 1. Hubungan laju korosi baja SS-304 dengan konsentrasi inhibitor ekstrak daun alpukat dalam medium korosif $\mathrm{HCl}$.

Hal ini dikarenakan ion klorida $(\mathrm{Cl})$ pada $\mathrm{HCl}$ bertindak sebagai ion agresif karena kemampuannya untuk menghancurkan lapisan pasif pada permukaan baja SS-304 dan mempercepat laju korosinya. Laju korosi terendah, yaitu pada baja dengan konsentrasi inhibitor $6 \%$ sebesar $0,37 \mathrm{~mm} / \mathrm{y}$. Hal ini menunjukkan bahwa laju korosi tidak dipengaruhi oleh bertambahnya konsentrasi inhibitor. Inhibitor memiliki batas optimum dalam membentuk proteksi untuk melindungi baja dari korosi.

Pemberian inhibitor berperan dalam mengurangi laju korosi dan dapat meningkatkan nilai inhibisi. Kemampuan untuk menginhibisi dapat diperoleh dari nilai efisiensi suatu ekstrak. Nilai efisiensi bergantung pada inhibitor yang digunakan. Hal ini menunjukkan efisiensi paling optimum yaitu pada konsentrasi $6 \%$ dengan nilai efisiensi mencapai sebesar $96,55 \%$.

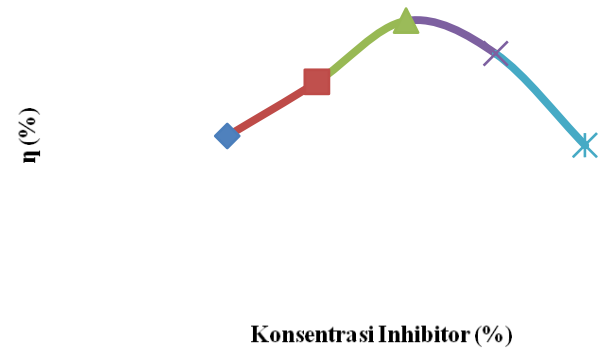

Gambar 2. Hubungan konsentrasi inhibitor dengan nilai efisiensi inhibitor ekstrak daun alpukat.

\section{Hasil Analisis XRD}

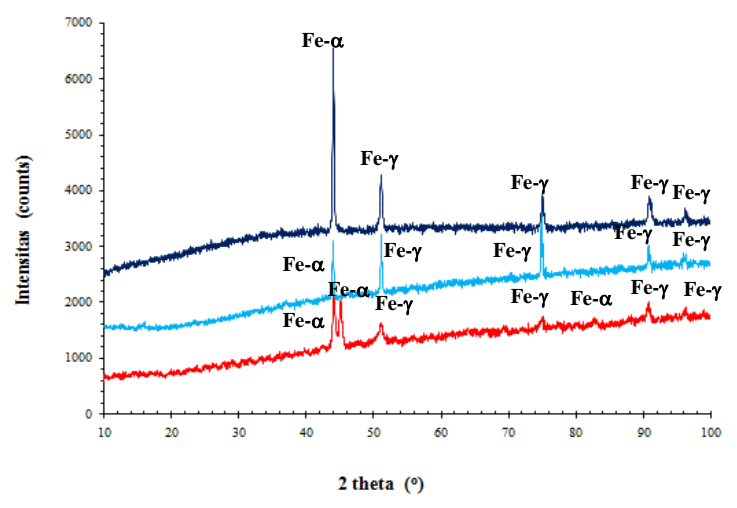

Gambar 3. Hasil difraktogram analisis XRD.

Analisis XRD dilakukan untuk mengetahui struktur dan fasa kristal yang terbentuk pada sampel baja. Hasil analisis XRD pada baja SS-304 raw, baja SS-304 dengan konsentrasi inhibitor $0 \%$ dan $6 \%$ dapat ditunjukkan pada Gambar 3. Pada Gambar 3 menujukkan intensitas yang dihasilkan pada sampel SS-304 dengan konsentrasi inhibitor 0\% lebih rendah dibandingkan SS- 
304 dengan konsentrasi inhibitor $6 \%$ yang mengindikasikan laju korosinya masih sangat tinggi sebelum ditambahkan inhibitor [10]. Dalam karakterisasi ini menggunakan data standar ICDD 01-0851410, 01-087-0721, dan 03-065-4150. Hal ini menunjukkan bahwa struktur kristal yang terbentuk pada kedua sampel baja yaitu struktur kristal BCC dan FCC. Struktur kristal yang teramati pada puncak difraksi terdiri dari campuran BCC dan FCC sesuai dengan karakteristik dari fasa SS-304 yaitu Fe- $\alpha$ (ferit) dan $\mathrm{Fe}-\gamma$ (austenit) [11].

\section{Hasil Analisis SEM-EDS}

Analisis SEM yang bertujuan untuk megetahui struktur mikro pada permukaan sampel dan analisis EDS bertujuan untuk mengetahui komposisi unsur atau senyawa yang terdapat pada permukaan sampel.

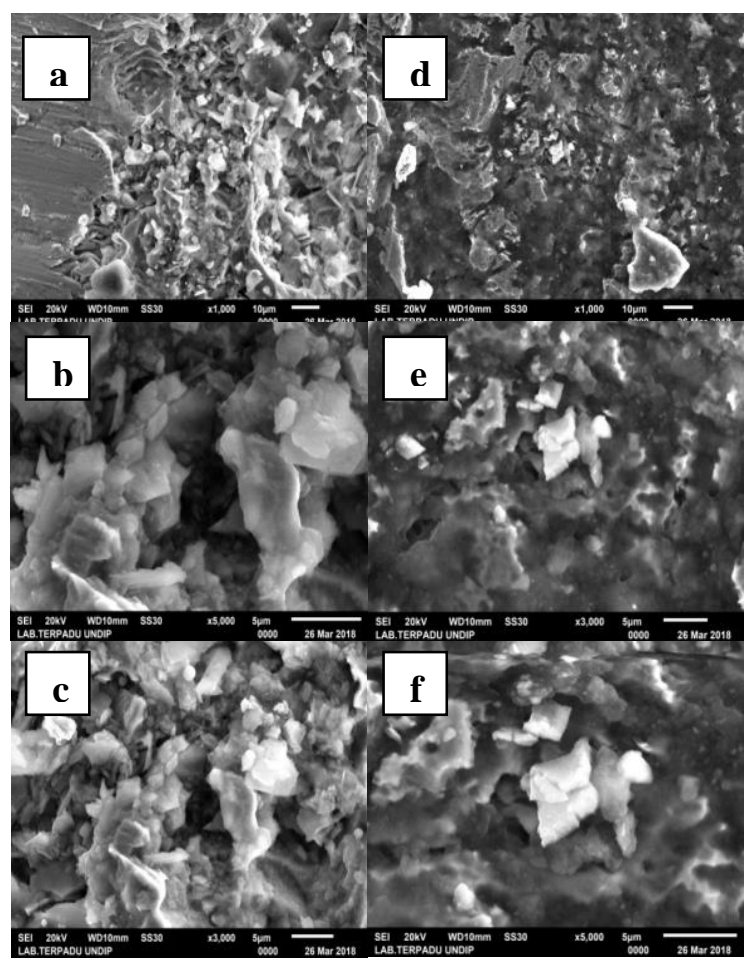

Gambar 4. Foto SEM baja SS-304 dengan inhibitor $0 \%$ dengan ukuran (a) 1000x (b) 3000x (c) 5000x dan baja SS-304 dengan inhibitor $6 \%$ dengan ukuran (d) $1000 \mathrm{x}$ (e) 3000x (f) 5000x.
Gambar 4(a) hampir seluruh permukaan baja terkena korosi yang menunjukkan adanya korosi seragam. Terlihat adanya retakan dan gumpalan pada permukaan baja. Dalam gumpalan tersebut terdapat lubang yang menandakan adanya korosi sumuran. Retakan dan lubang-lubang pada permukaan baja disebabkan oleh logam $\mathrm{Ni}$ yang dihasilkan saat peleburan. [12]. Baja tahan karat dan paduannya sangat rentan terhadap korosi sumuran [13]. Gumpalan yang dihasilkan memiliki ukuran yang berbeda seperti yang tampak pada Gambar 4(b) dan 4(c). Retakan yang terdapat pada sampel baja menandakan telah terjadi korosi retak tegang pada batas butir. Gambar 4(d) menunjukkan permukaan baja telah terlapisi oleh kerak. Kerak tersebut merupakan lapisan oksida tipis yang dihasilkan dari reaksi antara tanin dengan besi. Lubang dan retakan yang dihasilkan pada konsentrasi inhibitor $6 \%$ memiliki ukuran lebih kecil dibandingkan dengan lubang yang dihasilkan pada baja dengan konsentrasi inhibitor $0 \%$ (seperti pada Gambar 4(e)). Gambar 4(f) terlihat kerak yang melapisi permukaan sampel cukup tebal sehingga produk korosi yang dihasilkan berkurang. Hasil analisis EDS pada baja raw SS-304 ditunjukkan pada Gambar 5.

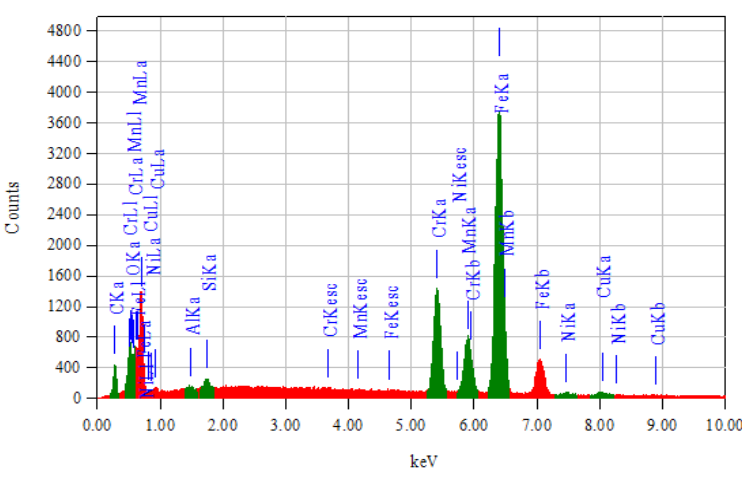

Gambar 5. Grafik hasil analisis EDS baja raw SS304. 
Gambar 5 menunjukkan bahwa baja SS304 memiliki unsur utama besi (Fe) sebesar $56,91 \%$. Sampel ini merupakan baja raw material yang tidak diberi perlakuan sehingga kandungan unsur besi $(\mathrm{Fe})$ masih sangat tinggi. Kemudian adanya unsur oksigen sebesar 4,07 \%. Kemungkinan oksigen berasal dari udara yang berikatan langsung dengan besi, oksigen ini dapat menyebabkan terjadinya korosi jika dibiarkan berinteraksi terlalu lama dengan baja. Unsur-unsur yang terdeteksi pada hasil EDS sesuai dengan hasil analisis yang terdapat pada OES.

Tabel 2. Unsur dan senyawa baja raw SS-304 dengan EDS.

\begin{tabular}{cccc}
\hline Unsur & Persentase & Senyawa & Persentase \\
\hline $\mathrm{C}$ & 15,16 & $\mathrm{C}$ & 15,16 \\
$\mathrm{O}$ & 4,07 & & \\
$\mathrm{Al}$ & 0,22 & $\mathrm{Al}_{2} \mathrm{O}_{3}$ & 0,38 \\
$\mathrm{Si}$ & 0,47 & $\mathrm{SiO}_{2}$ & 0,51 \\
$\mathrm{Cr}$ & 13,39 & $\mathrm{Cr}_{2} \mathrm{O}_{3}$ & 13,60 \\
$\mathrm{Mn}$ & 7,63 & $\mathrm{MnO}$ & 7,87 \\
$\mathrm{Fe}$ & 56,91 & $\mathrm{FeO}$ & 60,00 \\
$\mathrm{Ni}$ & 0,88 & $\mathrm{NiO}$ & 0,95 \\
$\mathrm{Cu}$ & 1,26 & $\mathrm{CuO}$ & 1,52 \\
\hline
\end{tabular}

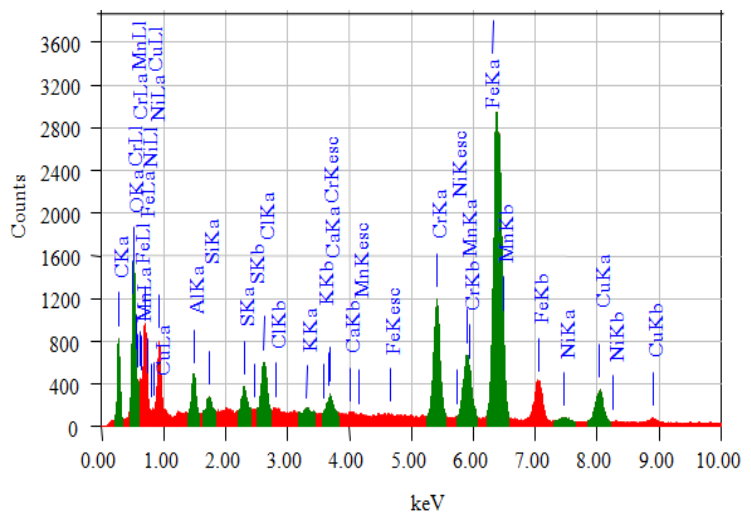

Gambar 6. Grafik hasil analisis EDS sampel baja SS-304 dengan inhibitor $0 \%$.
Gambar 6 menunjukkan bahwa baja SS-304 memiliki unsur yaitu besi (Fe) dengan persentase terbesar ada pada besi (Fe) sebanyak 26,08\%. Kemudian adanya unsur oksigen (O) pada baja SS-304 menunjukkan terdapat produk korosi pada permukaan baja akibat pembentukan oksida logam. Unsur karbon (C) yang tinggi disebabkan adanya kotoran yang menempel pada permukaan logam.

Berdasarkan Gambar 7 bahwa baja SS-304 yang direndam dengan konsentrasi inhibitor $6 \%$ pada medium $\mathrm{HCl} 1 \mathrm{M}$ memiliki unsur besi (Fe) sebesar 33,86\%. Kadar besi (Fe) pada sampel ini lebih besar dibandingkan dengan sampel baja SS-304 dengan inhibitor $0 \%$.

Tabel 3. Unsur dan senyawa baja SS-304 inhibitor 0\% dengan EDS.

\begin{tabular}{cccc}
\hline Unsur & Persentase & Senyawa & Persentase \\
\hline $\mathrm{C}$ & 24,20 & $\mathrm{C}$ & 24,20 \\
$\mathrm{O}$ & 19,07 & & \\
$\mathrm{Al}$ & 2,36 & $\mathrm{Al}_{2} \mathrm{O}_{3}$ & 2,40 \\
$\mathrm{Si}$ & 0,40 & $\mathrm{SiO}_{2}$ & 0,66 \\
$\mathrm{~S}$ & 0,57 & $\mathrm{SO}_{3}$ & 1,02 \\
$\mathrm{Cl}$ & 1,87 & $\mathrm{Cl}$ & 1,97 \\
$\mathrm{~K}$ & 0,42 & $\mathrm{~K} 2 \mathrm{O}$ & 0,48 \\
$\mathrm{Ca}$ & 0,54 & $\mathrm{CaO}$ & 0,75 \\
$\mathrm{Cr}$ & 8,81 & $\mathrm{Cr} \mathrm{O}_{3}$ & 10,11 \\
$\mathrm{Mn}$ & 6,62 & $\mathrm{MnO}$ & 6,96 \\
$\mathrm{Fe}$ & 26,08 & $\mathrm{FeO}$ & 41,27 \\
$\mathrm{Ni}$ & 1,54 & $\mathrm{NiO}$ & 1,93 \\
$\mathrm{Cu}$ & 7,51 & $\mathrm{CuO}$ & 8,24 \\
\hline
\end{tabular}

Tabel 4. Unsur dan senyawa baja SS-304 inhibitor 6\% dengan EDS.

\begin{tabular}{cccc}
\hline Unsur & Persentase & Senyawa & Persentase \\
\hline $\mathrm{C}$ & 34,92 & $\mathrm{C}$ & 41,92 \\
$\mathrm{O}$ & 19,85 & & \\
$\mathrm{Al}$ & 0,26 & $\mathrm{Al}_{2} \mathrm{O}_{3}$ & 0,46 \\
$\mathrm{Si}$ & 0,36 & $\mathrm{SiO}_{2}$ & 0,78 \\
$\mathrm{~S}$ & 0,36 & $\mathrm{SO}_{3}$ & 0,89 \\
$\mathrm{Ca}$ & 0,14 & $\mathrm{CaO}$ & 0,16 \\
$\mathrm{Cr}$ & 7,64 & $\mathrm{Cr}_{2} \mathrm{O}_{3}$ & 10,40 \\
$\mathrm{Fe}$ & 33,86 & $\mathrm{FeO}$ & 41,62 \\
$\mathrm{Ni}$ & 2,58 & $\mathrm{NiO}$ & 3,28 \\
$\mathrm{Cu}$ & 0,38 & $\mathrm{CuO}$ & 0,48 \\
\hline
\end{tabular}




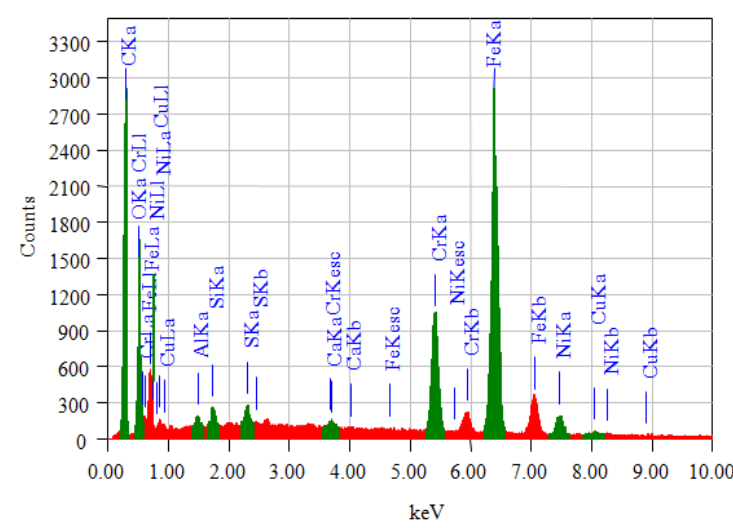

Gambar 7. Grafik hasil analisis EDS sampel baja SS-304 dengan inhibitor 6\%.

Hal ini dikarenakan pada sampel ini telah ditambahkan inhibitor ekstrak daun alpukat sehingga permukaan baja terlapisi oleh inhibitor. Hal ini menyebabkan kadar besi $(\mathrm{Fe})$ yang terkorosi menjadi sedikit. Serta adanya unsur oksigen (O) dengan persentasi $19,85 \%$ yang terbentuk baja dapat di pastikan telah terkorosi [14]. Pada baja dengan konsentrasi inhibitor $0 \%$ dihasilkan unsur $\mathrm{Cl}$ dengan persentase yang tergolong tinggi yaitu $1,87 \%$. Hal ini mengindikasikan bahwa baja sudah terkontaminasi akibat interaksi antara $\mathrm{HCl}$ dengan sampel [15]. Keberadaan unsur O dan $\mathrm{Cl}$ yang teridentifikasi menunjukkan adanya produk korosi dalam bentuk oksida logam. Oksida logam yang terbentuk dapat berupa senyawa $\mathrm{FeO}, \mathrm{Fe}_{2} \mathrm{O}_{3}$, dan $\mathrm{FeCl}_{2}$.

\section{KESIMPULAN}

Berdasarkan hasil dan pembahasan dapat disimpulkan bahwa konsentrasi ekstrak daun alpukat berpengaruh terhadap laju korosi yang dihasilkan yaitu laju korosi tertinggi terdapat pada baja SS-304 dengan konsentrasi inhibitor $0 \%$ sebesar 10,75 $\mathrm{mm} / \mathrm{y}$ dan laju korosi terendah pada baja SS-304 dengan konsentrasi inhibitor 6\% sebesar 0,37 $\mathrm{mm} / \mathrm{y}$. Efisiensi paling optimum terdapat pada baja SS-304 dengan konsentrasi inhibitor $6 \%$ pada medium korosif $\mathrm{HCl} 1 \mathrm{M}$ yaitu sebesar 96,55\%. Hasil analisis XRD dan SEM-EDS pada baja SS-304 dengan konsentrasi inhibitor
6\% menunjukkan struktur kristal yang terbentuk adalah BCC dan FCC dengan fasa $\mathrm{Fe}-\alpha$ dan $\mathrm{Fe}-\gamma$, lubang dan retakan lebih sedikit dibandingkan dengan konsentrasi inhibitor 0\%. Senyawa yang terbentuk yaitu $\mathrm{FeO}$ lebih dominan.

\section{DAFTAR PUSTAKA}

[1] Roberge, P. R. 2000. Handbook of Corrosion Engineering. Mc GrawHill. New York. Pp. 333-351.

[2] Supardi, R. 1997. Korosi Edisi Pertama. Tarsito. Bandung. Pp. 5658.

[3] Fontana, M. 1987. Corrosion Engineering. $3^{\text {rd }}$ edition Mc GrawHill. New York. Pp. 5-30.

[4] Ilim dan Hermawan. 2008. Studi Penggunaan Ekstrak Buah Lada, Buah Pinang dan Daun Tehsebagai Inhibitor Korosi Baja Lunak dalam Air Laut Buatan yang Jenuh $\mathrm{GasCO}_{2}$. Prosiding Seminar Nasional Sains dan Teknologi II. UniversitasLampung. Lampung. Pp. 257-256.

[5] Trethewey, K. R. and Chamberlain, J. 1991. Korosi untuk Mahasiswa danRekayasa. Gramedia Pustaka Utama. Jakarta. Pp. 27-28.

[6] El-Etre, A.Y., and Abdallah, M. 2000. Natural Honey as Corrosion Inhibitor for Metals and Alloys II Csteel in High Saline Water. Corrosion Science. Vol 42. Pp. 731738.

[7] Oguzie, E. E. 2007. Corrosion Inhibition of Aluminium in Acidic and Alkaline Media by Sansevieria Trifas-Ciata Extract. Corrosion Science. Vol. 49. Pp. 402-417.

[8] Maryati, S. 2007. Kandungan Kimia Daun Alpukat. Erlangga. Jakarta. Pp. 24-40.

[9] Lestari. P., wijama. S And Putri. W.I. 2014. Tannin Extraction from 
Avocado Leaves (Persea americana Mill.) as Natural Colorant (Study of Solute Ratio and Extraction Time). Skripsi. Universitas Brawijaya. Malang.

[10] Pakpahan, M. S., Ginting, E dan Suprihatin. 2015. Inhibisi Korosi Baja Karbon Rendah C-Mn Steel oleh Ekstrak Daun Teh (Camellia sinesis) dalam Medium Korosif. JURNAL Teori dan Aplikasi Fisika. Vol. 3. No. 2. Pp. $195-210$.

[11] Baldenebro, F. J., Gomez, C. D., Ramon, C., Susana, P. A., Manuel, J. P., Jose, E. L., Roberto, $M$ and Jose, M. H. 2015. Influence of Size on the Microstructure and Mechanical Properties of an AISI 304L Stainless Steel - A Comparison between Bulk and Fiber. Materials. Pp. $451-461$.

[12] Hidayat, T., Rhamdhani, M. A., E. Jak and P.C. Hayes. 2008. The Characterization of Nickel Metal
Pore Structures and Measurement of Intrinsic Reaction Rate During the Reduction of Nickel Oxide in $\mathrm{H}_{2}-\mathrm{N}_{2}$ and $\mathrm{H}_{2}-\mathrm{H}_{2} \mathrm{O}$ Atmospheres. Mineral Engineering. 21. Pp.Vol. 157 - 166.

[13] Chatterjee, U.K., S.K. Bose and S.K. Roy. 2001. Environmental Degradation ofMetals Corrosion Technology. Series 4. Marcel Dekker Inc. New York.

[14] Giri, A.S., Ginting, E., dan Suprihatin. 2017. Efektivitas Ekstrak daun Sirsak Sebagai Inhibitor Pada Baja Karbon API 5L dalam Larutan $\mathrm{NaCl} 3 \%$. Jurnal Teori dan Aplikasi Fisika. Vol. 5. No. 1. Pp. 46-47.

[15] Lukman dan Triwikantoro. 2009. Pengaruh Unsur Korosif pada Air Hujan terhadap Prilaku Korosi Baja Karbon Rendah. Seminar Nasional Pascasarjana. ITS. Surabaya. Pp. 143. 
Windi, dkk. Pengaruh Variasi Konsentrasi Ekstrak Daun Alpukat (Persen American M.) sebagai Inhibitor pada Baja SS-304 dalam Larutan $\mathrm{HCl} 1 \mathrm{M}$ 